\title{
CHINESE-STYLE PUBLIC SERVICE ADVERTISING ON CCTV: CHANGE AND CONTINUITY
}

\author{
Yan Liu \\ Ipsos (China) Marketing Consulting Co., Ltd., China
}

\begin{abstract}
This study traces change and continuity in the intended functions of Chinese-style public service advertisements (PSAs) from the perspective of structural functionalism. Chinese-style PSAs are divided into four periods corresponding to the leaders of the Chinese Communist Party (CCP): Deng (1979-1992), Jiang (1993-2002), Hu (2003-2012), and Xi (2013-present). Adopting the discourse-historical approach of critical discourse analysis, this study analyzes the interaction between Chinese-style PSAs and the corresponding social context in each period. The three intended functions of Chinese-style PSAs are found to be social norm transfer, legitimation and delegitimation, and the provision of a simple, dualistic mode of thinking. The limitations of the current study and orientations for future study are discussed.
\end{abstract}

Keywords: Chinese-style PSA, structural functionalism, intended functions, social context

\section{Introduction}

Since President Xi Jinping came to power, advertisements initiated by the propaganda departments of the Chinese government and the Chinese Communist Party (CCP) have proliferated. The increasing use of advertising, usually regarded as a consumer-marketing tool, to promote the Chinese nation, government, and the CCP is obvious both in China and worldwide (Mantesso and Zhou, 2019). Internationally, the main topics are the government's political views (e.g., China's sovereignty in the South China Sea), and national image (e.g., Chinese culture); while the topics are more diverse within China (e.g., "China Dream"). In China, they are called public service advertisements (PSAs), since they are unlike commercial ads, which usually promote a brand or product. However, these Chinese-style PSAs differ from other PSAs because of their political and propagandistic orientation. Also, since Chinese-style PSAs are not intended to influence voters by promoting a party, they also differ from the political ads usual in countries like the U.S.

To distinguish and define Chinese-style PSAs, it is necessary, first, to specify their initiators. Previous studies of PSAs have focused on non-governmental organizations (NGOs) and businesses. PSAs by NGOs usually "attempt to promote a specific action or viewpoint toward some institution, issue, or cause in order to serve the interest of the public" (Dessart, 1982). Topics include health issues, environmental issues, etc. PSAs by business organizations are usually called, in the relevant studies, corporate social responsibility communications (CSRs). Although such PSAs do raise awareness of critical issues (e.g., protecting the marine environment), they are intended, in the end, to promote the business organization. Besides enhancing the attitudes and behavior of consumers toward business organizations, CSRs are also expected to make favorable impressions on current or potential investors and employees (Du, et al., 2010).

In China, a socialist country under a single-party system, the media landscape differs from that in capitalist countries. The authorities always control the media, which they regard as essential to maintaining themselves in power. It is as a component of this media system that Chinese-style PSAs first emerged and have since proliferated. Although NGOs and business organizations do put out PSAs in China, Chinese-style PSAs are different by virtue of not only their initiators, but also their content. Instead of telling stories about a brand or a product, Chinese-style PSAs are about issues. In addition, Chinese-style PSAs present a distinct point of view; they take sides on the issues. They strongly "suggest" to audiences that they think and act in a specific way. The 
Ethics and Compliance Initiative (ECI) defines "values" as "core beliefs that guide and motivate attitudes and actions." In an advertising format, values are "sold" as "products." Thus, in this study, Chinese-style PSAs are defined as "advertisements initiated by state-owned media or propaganda-related departments in the Chinese government and the CCP, and [which] convey values promoted or consented by initiators."

Since Chinese-style PSAs emerged, they have not remained the same in form, content, and distribution channels. Since Xi took office, "new propaganda forms emulate the feel, technique, and tone of consumer advertising" (O'Shaughnessy, 2017). Norman Fairclough (1992) believes that analyzing discourse should not be isolated from the context in which the discourses emerge. Chinese-style PSAs, which are issued by the authorities, also show stable characteristics deeply rooted in Chinese society, although it is rapidly changing. This study traces change and continuity of values in Chinese-style PSAs and the corresponding social context. These PSAs are divided into four parts in this study, according to terms of CCP central leaders: Deng (19791992), Jiang (1993-2002), Hu (2003-2012) and Xi (2013-present). The structural functionalism perspective is adopted to understand the main problems faced by the initiators of PSAs in each period and what functions the initiators expected PSAs to have in dealing with those problems.

\section{Literature review}

\section{Structural functionalism}

This approach emphasizes the relationship between the parts and the whole of a society. It regards society as a system of interrelated and interactive subsystems (Kenneth and Bailey, 2001). Each social component has a function in keeping the system alive and stable. Structural functionalism can be traced back to the founder of sociology, Auguste Comte. Adopting the concept of a "system" from biology, Comte regarded society as a "social organism" and argued that the structural components of a society contribute to the maintenance of the social system (Turner and Maryanski, 1979). Herbert Spencer extended the analysis of social parts based on Comte's ideas. Inspired by the theory of biological evolution, he introduced the concept of "function" to analyze social components' contributions to the system. Spencer believed in the "survival of the fittest" and adopted the idea of the system's "needs" to explain the existence and the functions of its social parts (Liu, 2008).

Inheriting Comte's concern with order, Emile Durkheim extended Spencer's analysis of "functions." Durkheim argued that both the historical causes and the current functions of a social structure should be considered to explain how it satisfies a society's need for integration (Turner and Maryanski, 1979). American sociologist Robert K. Merton agreed that analyzing social structure should include its context, but he questioned the implication in past functional analysis, which is that social structures always have a positive contribution to a system. According to Merton, in a specific context, a social structure could make positive (functional), negative (dysfunctional) or no (nonfunctional) contributions to the system. He also argued that the motivations of the actors in a social system should be analyzed to explore "intended functions" of social structures; these are the functions that actors expect social structures to have in a specific context (Turner and Maryanski, 1979).

Another influential sociologist, Talcott Parsons, elaborated "functional prerequisites" as necessary conditions for social structures to function in a social system. For instance, each society has fundamental values and norms, which individuals internalize during socialization. Transformation of values and norms depends on conditions, including the operation of organizations and institutions that convey them (Cohen, 1968).

\section{Functions of mass communication}

Adopting a structural functionalist approach to mass communication studies, Harold Lasswell conceived of mass media as having three functions: surveilling the environment, correlating social parts, and transmitting the social heritage. Charles Wright added "entertainment" as a fourth function. 
"Surveilling the environment" means that the mass media offer individuals and organizations information about the environment they live in. Lasswell's "correlation of parts of society" is similar to Wright's "explanation and provision." It means that mass media coordinate social structures by enabling communication among them. Lasswell's "transmission of social heritage" is defined as "socialization" by Wright. Mass media convey to individuals the modes of behavior acceptable in the society; they are to learn to act in specific ways. The "entertainment" function added by Wright means that mass communication provides individuals with entertainment (Liu, 2008).

According to another influential view formulated by Lazarsfeld and Merton (1948), mass media have three functions: narcotizing dysfunction, conferring status, and enforcing social norms. The narcotizing dysfunction means that audiences spend so time gathering information from the media that they spend too little time and energy actually doing things. The status-conferral function is status legitimation of specific individuals, groups, organizations, and issues. Mass media enforce social norms by creating the social conditions for disseminating certain values in society. These theorists emphasized that these functions are abstracted from the society in which the mass media operated. Thus, important structural factors like the ownership and control of the media were temporarily ignored (Lazarsfeld and Merton, 1948).

The functions of media mentioned above are proposed in Western context, the media system in which operates relatively independently from government. As stated above, the media system in China is almost completely controlled by the authorities, which different greatly from the context in which the functions mentioned above are proposed. Understanding Chinese-style PSAs' motives, which is done by analyzing problems the authority faces in social context, helps to explain what functions the authority expects them to have. In this way, this study aims to contribute to theory media function. This study adopts Merton's view that actors' motivations should be explored to understand the "intended functions" of social structures. By considering both their motives and the social context in analyzing Chinese-style PSAs' intended functions, the author aims to explore the functions of mass media beyond those proposed by Lasswell, Wright, Lazarsfeld, and Merton. Formally:

RQ1: What are the main problems in the social context faced by the initiators of Chinese-style PSAs' in each period?

RQ2: What are initiators' intended functions of Chinese-style PSAs in each period?

\section{Method and data sources}

In this study, Chinese-style PSAs are divided according to the terms of the CCP's leaders: Deng Xiaoping (1978-1992), Jiang Zemin (1993-2002), Hu Jintao (2003-2012) and Xi Jinping (2013-present).

This division is made because Chinese society has been experiencing rapid changes since the Reform and Opening. Although the authorities have always controlled the media, different policies have been applied to the media in these different periods as the society faced different problems and the styles of leadership shifted. According to Tai (2014), these changes in media policy have had three aspects: the degree of restricting unwanted content, the technique in guiding public opinion about sensitive content, and the promotion of favorable content. This study focuses on the changes and continuity of Chinese-style PSAs in the promotion of favorable content.

Critical Discourse Analysis (CDA) is the approach adopted in this study. CDA regards discourses as "social practice" that should be interpreted in the context in which they were produced. Discursive units studied under this approach are commonly large, like institutional, political, media discourses (Wodak and Meyer, 2001). The CDA approach taken in this study is in the spirit of Ruth Wodak's (2004) Discourse-Historical approach, which focuses on social problems. The historical and social context is involved in interpreting the motives of those who create the discourses. 
As for data sources, Chinese-style PSAs broadcast on China Central Television (CCTV) are included, while those on other TV channels or in other media are excluded, for two reasons. First, as a state-owned medium, CCTV serves as the "mouthpiece of [the] CCP, government and people" (CCTV official website, 2019). The content broadcast on CCTV is subject to strict censorship by state authorities. Thus, the values in Chinese-style PSAs on CCTV reflect, more precisely than alternative media, the authorities' intentions. Secondly, according to Wiki (2019), CCTV has the highest audience ratings in mainland China. Its wide appeal to audiences all across society and high reputation make it the most powerful medium in China.

The data and the material analyzed are from two sources. When the author was a postgraduate student, in 2016, she had no access to the official archive of PSAs then being broadcast on CCTV and was unable to interview CCTV staff members who had created or selected the PSAs in the former three periods. Therefore, for data and the material pertaining to those periods, the terms of Deng, Jiang, and Hu, this study draws on secondary materials from previous academic studies, documents, and reports. For information pertaining to Xi's term from 2013-16, the source is a first-hand collection of a hundred pieces of Chinese style PSA's, which the author collected by searching both CCTV official website and video websites. Quantitative content analysis was done based on this collection. Values conveyed by Chinese-style PSAs are analyzed by three criteria to understand intended functions: 1) what values that the PSAs convey (what do they "suggest" audiences do or think about what issue), 2) where the values are rooted (e.g., traditional Chinese culture, ruling idea, policies, etc.), and 3) who would benefit most if these values were successfully internalized (e.g., CCP, the government, people, etc.). The three dimensions were also adopted to develop a codebook (inter coder reliability $=0.91$ ).

\title{
Analysis
}

\section{Deng's term (1978-1992): the introduction of Chinese-style PSAs}

As a reformer, Deng criticized the idea of "taking class struggle as the key link," which had been ideologically paramount when Mao was in power. He also disavowed the Great Leap Forward, an ultra-left economic program under the planned economy system (Database of the Reform and Opening, 2019). Deng was convinced that the only way to enable China to develop was to strengthen the economy and improve the peoples' standard of living. Thus, he established private ownership and a market-oriented economy under the planned economy. To advance economic policies, he argued that "practice is the sole criterion for testing truth," indicating that ideological control can cede ground to economic development. However, Mao's ideological legacy had not entirely lost its grip, so commercial ads, inevitable in new economic system, were rejected by conservatives as "capitalism's things" right from the start.

In June 1987, CCTV established an independent ad department, initially just for commercial ads. According to the former chief of the ad department (as revealed in 2002 during an interview by Hua), most of this new department's staff came from news production departments. These non-professional "ad men" created a program called Guanger Gaozhi for Chinese-style PSAs in October, 1987. The staff wanted most of all to show professional propaganda skills so as to gain the leaders' support and blunt the criticism of commercial ads, but they also believed that the media should educate audiences about right and wrong. The purpose of setting up Guanger Gaozhi was announced this way:

\begin{abstract}
"Through reminding, criticizing, persuading, Guanger Gaozhi conveys thoughts, behaviors and moralities which are good for the development of society. It aims to change values and morality of individuals, cultivate good social atmosphere, and promote civilization." (Tang, 2014)
\end{abstract}

In this period, the main problems faced by the authorities were how to "loosen up the monolithic ideology that had predominated since Mao's time" and develop the economy in practice. Also, with the development of the economy and the advancement of private ownership, some new social phenomena emerged; some people acted in uncivilized ways. Thus, the content and intended functions of Chinese-style PSAs were two-fold. First, as stated in the announcement, Chinese-style PSAs were expected to educate audiences to do good for society. Most of the Chinese-style PSAs in this period promoted behavior like saving energy, using roads safely, 
protecting the environment, etc. For instance, in an Chinese-style PSA, pictures of earth were showed to persuade audience to categorize garbage in daily life. Before that, there is no idea of categorizing garbage for more efficient way to deal with them in China. This ad aimed to introduce a lifestyle which is more modern and environmental-friendly. Second, to "loosen up the monolithic ideology that had predominated since Mao's time", the values expressed in these Chinese-style PSAs were not very political. Values were not those instilled by ideology but mainly those of traditional Chinese culture (e.g., respecting the old) and those emerging after the Reform and Opening (e.g., civilization). Chinese society and its people were to benefit if these values were internalized. Control was loosened, and the political propaganda was toned down, but the mass media certainly could not promote pluralism.

\section{Jiang's term (1993-2002): the emergence of political orientation and reflection of social problems}

The Reform and Opening brought great change to China. Although Deng affirmed a market-oriented economy under the control of a planned economy during an inspection tour of the south and at the 14th National Party Congress of the CCP in 1992, there were still disagreements about the new economic system.

To legitimate the new economic policies, Jiang, a reformer who succeeded Deng, officially established the concept of the Socialist Market Economy, and wrote the Deng Xiaoping theory into the CCP's Party Constitution. However, with the economy growing rapidly, values grew more diverse, and new social problems emerged. To control them, a new strategy was promoted at the national level in 1996: the construction of a spiritual civilization with socialist features (Zhang, 2014). A new branch of the propaganda department (The Central Commission for Guiding Cultural and Ethical Progress) was established in 1997 to take charge of advancing this strategy, whereby media were utilized to convey a unified ideology.

Recognizing the potential power of PSAs, the propaganda department engaged in promoting Chinese-style PSAs by organizing a nationwide "Month of PSAs" from 1996. This action not only expanded the influence of Chinese-style PSAs but also affirmed them as political communication (Hua, 2002). This is the first characteristic of Chinese-style PSAs in Jiang's term: the re-emphasis on political orientation. PSAs continued conveying traditional Chinese morality (e.g., respect for the old) but also new values related to the new economic system (e.g., the new morality of professionalism, new social ethics, the importance of technology and education in development), the ruling idea (e.g., promoting the policies and achievements of the CCP's leaders), patriotism, etc. For example, a PSA named "Hoist One Flag, Love One Family" shows people from various ethnic backgrounds, in different occupations, and of different ages watching the national flag as it is hoisted. It promoted patriotism by presenting everyone as loving China. By promoting the values of unity, Chinese-style PSAs were expected to legitimate and create a positive atmosphere for the CCP's power and policies.

The second characteristic of Chinese-style PSAs in this period is their reflection of social problems. For instance, economic reform, especially the privatization of state-owned companies, led to layoffs, causing anxiety in society. Chinese-style PSAs were designed convey the message that workers should be strong and rebuild their own lives. In a PSA called "Start Again from the Beginning", workers were encouraged to face reality and find ways other than employment at state-owned enterprises to support their families. These PSAs were to legitimate social reality and maintain social stability by relieving anxiety.

In conclusion, the main problems faced by the authorities during Jiang's term were how to legitimate the economic reform and to deal with ideological disputes and the new social problems. By instilling patriotism and legitimizing the CCP and its policies, Chinese-style PSAs were to create public opinion conducive to advancing economic development in the Socialist Market Economy while keeping the CCP's power stable. 


\section{Hu's term (2003-12): increased promotion of political ideology and traditional values and reflection of historic events}

Instead of privatizing more state-owned companies, Hu conducted conservative economic policies. State-owned companies thrived because of both favorable policies and capital injection from the government, so they took over private companies (Li and Cary, 2011). Thus, although the economy grew fastest during Hu's term, some people complained that the growth was mainly a dividend of the Reform and Opening (Zhang, 2012). Also, social inequity and other social problems kept worsening in this period. There were "problems in industrial structure, transformation, migrant workers and left-behind children in rural areas, aging populations, employment of college graduates, ecological civilization, corruption..." (Zhang, 2014). Hu's government did devise policies to enhance social equity, like rescinding the agriculture tax and establishing basic medical insurance, but only scratched the surface. Thus, Hu was criticized as too conservative in addressing political problems and not devising fundamental policies to relieve increasing social problems (Johnson and Bradsher, 2012).

Although conservative in economic policies, Hu's government took the initiative in ideological control by strictly controlling the information accessible to the masses. For example, the authorities tried - but ultimately failed - to pre-install a software program called "Green Dam" on PCs in China to prevent adolescents from seeing pornography and politically sensitive content. Other efforts to censor the Internet included deleting unwanted online comments on SNS (Jacobs, 2009). Besides banning unwanted content, the authorities promoted the favorable sort by increasing their control over PSAs, as by regulating their time. Thus the State Administration of Radio, Film and Television (SARFT) conducted Temporal Administrative Measures for Broadcasting Radio and TV Advertisements, which stipulated that PSAs should take up more than 3\% of total ad time every day on TV. Chinese-style PSAs in this period focused, in their content, political ideology, and emphasis of traditional Chinese culture and values, on guiding public emotions and opinions about disasters and other events.

Their political ideology derived from Hu's three ruling ideas. Hu put forward, first, the "Scientific Outlook on Development," which was written into the CCP's Party Constitution. In essence, this ruling idea consists in regarding human well-being as the point of developing the economy and people themselves comprehensively, systematically, and continuously. Second, he emphasized the "socialist value of honor" and "harmonious socialist society" as guiding values. In many Chinese-style PSAs, the very words "socialist value of honor" were in the lyrics of songs or ballads. Singing "patriotism is honorable, betraying the motherland is shameful; serving the people is honorable, departing from the people is shameful" (Hu, 2006), these PSAs "tell" the people directly how the authorities expect them to act and think.

The concept of a "harmonious socialist society" reflects Hu's idea of partially adopting traditional Confucianism as a way to order current society; it was part of a trend in Chinese-style PSAs to expand their scope to include topics from traditional Chinese culture and values. For example, a series of PSAs called "Chinese festivals and solar terms" aimed at instilling pride in Chinese culture and a sense of responsibility for transmitting it. Using words like "our festival" as a slogan, they implicitly promote social unity.

Some disasters and historical events contributed to the social context during Hu's term: the outbreak of SARS in 2003, the disastrous snowstorm in the south in 2008, the Wenchuan earthquake in 2008, and Peking Olympic Games in 2008. Chinese-style PSAs focused on them. "Unite (we are together)" and "love for country and compatriots" were always highlighted as ways that Chinese people should cope with disasters or glory in historical events.

As stated above, ideological control during Deng's term was loosened for the sake of economic reforms. However, in Hu's term, social inequity and social changes amidst economic development were worsening. Therefore, ideological control over the media was intensified. The authorities banned unwanted content, especially public discussions of politically sensitive topics, and unified political ideology was promoted more intensely to enhance unity among all social classes. Chinese-style PSAs worked, like the ban on unwanted 
content, to make public opinion approve of the CCP's power and to calm negative emotions about expanding social inequity and social changes.

\section{Xi's term (2013-present): renewed promotion of a uniform ideology}

When Xi came to power, social problems were worsening. Even more ominously, the Chinese economy's growth rate was starting to fall. Although $\mathrm{Hu}$ had been criticized for failing to develop policies that could essentially boost economic development while relieving social problems, high GDP growth during his term still enabled the Chinese people to believe in the CCP's leadership while containing their feelings about those problems. However, during Xi's term, the slowing of growth has deepened people's doubts about, and even distrust of, the CCP, while social problems like unemployment, corruption, social inequity, and environmental problems have worsened (Gao, 2014). Also, due to the expansion of SNS, ordinary citizens can now post news and express individual opinions, which spread fast through the population, creating widespread negative attitudes toward the authorities (Deng, 2019).

If $\mathrm{Xi}$ is to keep the $\mathrm{CCP}$ and himself in power, he must rebuild the people's trust in the CCP and the Chinese government (Gao, 2014). Also, Xi's distinctive style of exercising power has led him to some of his decisions. For the economy, he has touted "supply-side structural reform" and deepened the involvement of the CCP and the government in the economy. Within the CCP, he has fought corruption and amassed personal power. In addition, of the four Chinese leaders since Mao, Xi has exerted the strictest ideological control through the media, as is clear from it intensified promotion of favorable content (e.g., of Xi's ruling idea, Xi's pro-people stance, traditional Chinese values, patriotism, support for the CCP) and stricter exclusion of unwanted content (e.g., restriction of foreign TV programs and discussions of politically sensitive topics online). As stated above, relatively easy access to PSAs in Xi's term has made it possible for people to analyze his promotion of favorable content.

One hundred Chinese-style PSAs are analyzed. Table 1 shows what values were conveyed. Caring for the family appeared most frequently. In many societies and cultures, the family is what people treasure most. In Chinese culture, as well, family matters. However, there is a culturally specific implication: the country is the family for all Chinese. The connection between the "big family," country, and the "small family," the individual family, is rooted in Chinese tradition and has been officially promoted by Xi for a political purpose (Shen, 2015). Patriotism should be enhanced by connecting country to family in some PSAs conveying values of "caring for family." "Core socialist values" (19\%) and the "China dream" (14\%) are Xi's ruling ideas. Like Hu's "socialist value of honor," they also show how authorities expect people to act. It is especially clear in the case of core socialist values, which describe "ideal China" on three levels: country (prosperity, democracy, civilization, harmony), society (freedom, equity, justice, rule of law), and individual (patriotism, professionalism, dedication, honesty, friendliness). These values are the explicit content of Chinese-style PSAs. Other values include caring for others (16\%), keeping historical events in mind (9\%), devotion to society $(6 \%)$, combating corruption (4\%), and fighting the Chinese people's way $(4 \%)$..

Table 1: Values conveyed in Chinese-style PSAs in Xi's term $(N=100)$

\begin{tabular}{cc}
\hline Values & Percentage \\
\hline the power of the CCP or Xi & $45 \%$ \\
\hline Society & $35 \%$ \\
\hline Family & $26 \%$ \\
\hline The government & $23 \%$ \\
\hline Individuals & $12 \%$ \\
\hline Others & $1 \%$ \\
\hline
\end{tabular}


Table 2 presents who would benefit most if values are successfully internalized. Although values conveyed by Chinese-style PSAs, if internalized, would benefit many in society, the CCP would benefit most. As stated above, the results coincide with the media policies generally adopted by Xi. They aim to use the power of the media to maintain his power.

Table $2:$ Beneficiaries of values conveyed in Chinese-style PSAs in Xi's term $(N=100)$

\begin{tabular}{cccc}
\hline Values & Percentage & Values & Percentage \\
\hline Caring for family & $21 \%$ & Devotion to society & $6 \%$ \\
\hline $\begin{array}{c}\text { Core socialist values (Xi's } \\
\text { ruling idea) }\end{array}$ & $19 \%$ & Combat corruption & $4 \%$ \\
\hline Caring for others & $16 \%$ & Fight Chinese people's way & $4 \%$ \\
\hline China dream (Xi's ruling idea) & $14 \%$ & Civilization & $1 \%$ \\
\hline Keep historical events in mind & $9 \%$ & Others & $8 \%$ \\
\hline
\end{tabular}

In conclusion, the problems that $\mathrm{Xi}$ is facing include a lower growth rate of the economy, spreading social problems, and increasing distrust in that CCP and the government Xi's government has intensified media policies since Hu's term. The government aims to restrict diversity of values and persuade the masses to accept a unified ideology. By simultaneously restricting unwanted content (and meting out punishments for violations) and promoting favorable content more vigorously, Chinese-style PSAs present the masses with the "safe" ways they should think, speak, and act. The goal is to maintain the CCP and Xi in power.

\section{Discussion}

By analyzing the intended functions of Chinese-style PSAs in the varying social context, both change and continuity were observed. There are three aspects to these intended functions: legitimation and de-legitimation, social norm transfer, and provision of a simplified, dualistic mode of thinking.

The legitimation function corresponds to "status-conferral" as understood by Lazarsfeld and Merton. Thus, Chinese-style PSAs in Jiang's term were to legitimate the Reform, the Opening, and the difficult social reality caused by the new policies (e.g., layoffs of workers in formerly state-owned enterprises). In Xi's term, PSAs aim to legitimate his leadership and the CCP's power. Moreover, the author argues that this legitimation aims not only to promote individuals, organizations, or issues, but also to limit the promotion of particular values. As mentioned above, Chinese-style PSAs during Deng's term did not try to instill strict ideology. That policy could, of course, be regarded as de-legitimizing ideological values in Chinese-style PSAs.

The function of social norm transfer corresponds to both Lasswell's "transmission of social heritage" and Lazarsfeld and Merton's "enforcement of social norms". And indeed, traditional Chinese values (e.g., respecting the old, treasuring the family) have appeared frequently in Chinese-style PSAs in every period. These values are approved by the authorities as the social heritage to be transmitted. The authorities also expect audiences to internalize the new values (e.g., civilization, democracy, etc.) that are emerging as society develops and which are rooted in ruling ideas (e.g., in Hu's "socialist values of honor," Xi's "socialist core values"). Since the values conveyed by these PSAs coincide with what benefits the authorities, the second intended function of Chinesestyle PSAs is to persuade audiences to internalize the values of assenting to the authorities.

Providing a simple, dualistic mode of thinking is a relatively unique function in China, a country under a singleparty system. Chinese-style PSAs harmonize with other social structures to achieve this aim. For instance, unwanted online comments by SNS users are usually deleted to stop widespread discussions. By banning unwanted content and punishing whoever releases it, the authorities "teach" people how not to think and act. Chinese-style PSAs take a positive tack by aiming to "teach" people the "right" way that authorities expect them 
to think and act. In this way, the masses gradually "learn" the "safe" way to behave through media policies, without thinking for themselves.

\section{Conclusion, limitation and future studies}

This study, relying on the structural functionalism perspective and taking into account the social contexts of each period, traces change and continuity in Chinese-style PSAs since they emerged during Deng's term.

When Deng held power, strict ideological control made concessions to the Reform and Opening and the new market-oriented economy, so that Chinese-style PSAs emphasized the new values emerging under the new economic policy as well as traditional Chinese values. In Jiang's term, Chinese-style PSAs were more political, to legitimize economic reform and the new social reality. In Hu's term, Chinese-style PSAs increasingly emphasized unified ideological values, to strengthen social unity. In Xi's term, Chinese-style PSAs aim to instill significantly stronger ideology to maintain the power of the CCP and Xi himself.

Viewing Chinese-style PSAs as a component of the media system, the author concludes that they have three intended functions. Their social norm transfer corresponds to mass media's "transmission of social heritage" as understood by Lasswell and "enforcement of social norms" as understood by Lazarsfeld and Merton. Their legitimation function corresponds to "status-conferral" as understood by Lazarsfeld and Merton. In addition, the author, noting the scarcity of ideological values in Chinese-style PSAs in Deng' s term, extends the concept of legitimation function by proposing the concept of de-legitimation. What is more, based on the social context in China, the author proposes "providing a simple dualistic thinking mode" as a function of Chinese-style PSAs, which is a possible extension of the mass media's function.

As for limitations, the author lacks access to archives of Chinese-style PSAs on CCTV in the three earlier periods, so the sources are mainly secondary materials, making the analysis less than fully comprehensive. Besides, firsthand, in-depth interviews of the producers of Chinese-style PSAs and officers in propaganda departments should be included to explore the initiators' motivations more directly.

Future studies could be two-fold. First, since this study mainly explores the functions of Chinese-style PSAs as intended by the authorities, their actual effects could be further explored. Second, the expected functions of "delegitimation" and "providing simplified dualistic thinking mode" could be examined in different cultures and media environments.

\section{References}

Cohen, P. S., 1968, Modern social theory (London, U.K.: Heinemann Educational Book Ltd).

Database of the Reform and Opening, Data of access: 10/03/2019.

http://www.reformdata.org/records/1992.shtml

Deng, Y. W., 2019, Nine challenges CCP is facing in politics. BBC News in Chinese, 31 January.

Dessart, G., 1982, More Than You Want to Know About PSAs: A Guide to Production and Placement of Effective Public. Service Announcements on Radio and Television, National Broadcast Association for Public Affairs, Boston, U.S.

Du, S., Bhattacharya, C.B., and Sen, S., 2010, Maximizing business returns to corporate social responsibility (CSR): the role of CSR communication, International Journal of Management Reviews, 10(1), 8-19.

ECI, Ethics \& compliance initiative, Data of access:10/03/2019.

https://www.ethics.org/resources/free-toolkit/definition-values/

Fairclough, N., 1992, Discourse and social change (Cambridge, U.K.: Polity Press).

Gao, W. Q., 2014, Comments on China: the 5th leadership Xi Jinping. BBC News in Chinese, 17 November.

Hua, W., 2002, From propaganda of advertising to advertising of propaganda-Political economic analysis of Chinese PSAs, Master thesis, The Chinese University of Hong Kong, HK, China. 
Huang, A. W., 2016, Xi intensified media control and enhanced personal power. The New York Times in Chinese. 23 February.

Jacobs, A., 2009, China requires censorship software on new PCs. The New York Times, 8 June.

Johnson, I., and Bradsher, K., 2012, Hu Jintao concluded the ten years he was in power. The New York Times in Chinese, 9 November.

Kenneth, D., and Bailey, B., 2001, Systems theory. In: Handbook of sociological theory, edited by J. H. Turner. (New York: Kluwer Academic/Plenum Publishers), pp. 379-404.

Lazarsfeld, P. F., and Merton, R. K., 1948, Mass communication, popular taste and organized social action. In: The communication of ideas, edited by L. Bryson. (New York: Cooper Square Publishers), pp. 95-118.

Li, C., and Cary, E., 2011, The last year of Hu's leadership: Hu's to blame? The Jamestown Foundation, 20 December.

Lim, R., Sung, Y. L., and Lee, W., 2016, Judge me not by my words but by how I say them: the role of CSR communication style in consumer response. Proceedings of the 36th American Academy of Advertising Conference Proceedings, Seattle, Washington, U.S. July, pp. 234-243.

Liu, H. L., 2009, Theory of mass communication: paradigm and school (Beijing, China: Renmin University of China Public House).

Mantesso, S., and Zhou, C., 2019, Never tell all the truth: Internationalization of Chinese media and demography crisis. ABC News. 8 February.

O'Shaughnessy, N., 2017, The politics of consumption and the consumption of politics: How authoritarian regimes shape public opinion by using consumer marketing tools. Journal of Advertising Research, 17 (2), 121 126.

Shen, Y. X., 2015, Understanding Xi Jinping's view of family and country. People.cn, 6 October.

Tai, Q., 2014, China's media censorship: A dynamic and diversified regime. Journal of East Asian Studies, 14(2), 185-210.

Tang, G. H., 2014, Transform of topics of PSAs on CCTV from 1987 to 2013, Master thesis, Yunnan Normal University, Yunnan, China.

Turner, J. H., and Maryanski, A., 1979, Functionalism (San Francisco, U.S.: Phoenix Publishing Services).

Wodak, R., 2004, Critical discourse analysis. In: Qualitative research practice, edited by Seale, C., Gobo, G., Gubrium, J. F., and Silverman, D. (London, U.K.: Sage Publications Ltd), pp. 185-201.

Wodak, R., and Meyer, M., 2001, Methods of critical discourse analysis (London, U.K.: Sage Publications Ltd).

Zhang, C., 2014, Social change and Chinese PSA on television from 1978 to 2012, PhD thesis, Hunan Normal University, Hunan, China.

Zhang, W., 2012, Analysis: Hu and Wen's era is when the social conflictions accumulated. BBC China, 20 August. 